\title{
Midkine Is Elevated After Multiple Trauma and Acts Directly on Human Cardiomyocytes by Altering Their Functionality and Metabolism
}

OPEN ACCESS

Edited by:

Lukas Martin

University Hospital RWTH

Aachen, Germany

Reviewed by:

Juerg Hamacher,

Lindenhofspital, Switzerland

Sergio Iván Valdés-Ferrer,

Instituto Nacional de Ciencias

Médicas y Nutrición Salvador Zubirán

(INCMNSZ), Mexico

Sandra Kraemer,

University Hospital RWTH

Aachen, Germany

*Correspondence:

Miriam Kalbitz

miriam.kalbitz@uniklinik-ulm.de

Specialty section:

This article was submitted to

Inflammation,

a section of the journal

Frontiers in Immunology

Received: 29 April 2019

Accepted: 29 July 2019

Published: 21 August 2019

Citation:

Lackner I, Weber B, Baur M, Haffner-Luntzer M, Eiseler T, Fois $G$ Gebhard F, Relja B, Marzi I, Pfeifer R,

Halvachizadeh S, Lipiski M,

Cesarovic N, Pape H-C, Kalbitz M and

TREAT Research Group (2019)

Midkine Is Elevated After Multiple

Trauma and Acts Directly on Human

Cardiomyocytes by Altering Their

Functionality and Metabolism.

Front. Immunol. 10:1920.

doi: 10.3389/fimmu.2019.01920

\begin{abstract}
Ina Lackner ${ }^{1}$, Birte Weber ${ }^{1}$, Meike Baur ${ }^{1}$, Melanie Haffner-Luntzer ${ }^{2}$, Tim Eiseler ${ }^{3}$, Giorgio Fois ${ }^{4}$, Florian Gebhard ${ }^{1}$, Borna Relja ${ }^{5}$, Ingo Marzi ${ }^{5}$, Roman Pfeifer ${ }^{6}$, Sascha Halvachizadeh ${ }^{6}$, Miriam Lipiski ${ }^{7}$, Nikola Cesarovic ${ }^{7}$, Hans-Christoph Pape ${ }^{6}$, Miriam Kalbitz ${ }^{1 *}$ and TREAT Research Group

${ }^{1}$ Department of Traumatology, Hand, Plastic, and Reconstructive Surgery, Center of Surgery, University of UIm, Ulm, Germany, ${ }^{2}$ Institute of Orthopedic Research and Biomechanics, University of UIm, UIm, Germany, ${ }^{3}$ Department of Internal Medicine I, University of UIm, UIm, Germany, ${ }^{4}$ Institute of General Physiology, University of UIm, Ulm, Germany, ${ }^{5}$ Department of Trauma, Hand and Reconstructive Surgery, Goethe University Frankfurt, Frankfurt, Germany, ${ }^{6}$ Department of Trauma, University Hospital of Zurich, Zurich, Switzerland, ${ }^{7}$ Department of Surgical Research, University Hospital of Zurich, Zurich, Switzerland
\end{abstract}

Background and Purpose: Post-traumatic cardiac dysfunction often occurs in multiply injured patients (ISS $\geq 16$ ). Next to direct cardiac injury, post-traumatic cardiac dysfunction is mostly induced by the release of inflammatory biomarkers. One of these is the heparin-binding factor Midkine, which is elevated in humans after fracture, burn injury and traumatic spinal cord injury. Midkine is associated with cardiac pathologies but the exact role of Midkine in the development of those diseases is ambiguous. The systemic profile of Midkine after multiple trauma, its effects on cardiomyocytes and the association with post-traumatic cardiac dysfunction, remain unknown.

Experimental Approach: Midkine levels were investigated in blood plasma of multiply injured humans and pigs. Furthermore, human cardiomyocytes (iPS) were cultured in presence/absence of Midkine and analyzed regarding viability, apoptosis, calcium handling, metabolic alterations, and oxidative stress. Finally, the Midkine filtration capacity of the therapeutic blood absorption column CytoSorb ${ }^{\circledR} 300$ was tested with recombinant Midkine or plasma from multiply injured patients.

Key Results: Midkine levels were significantly increased in blood plasma of multiply injured humans and pigs. Midkine acts on human cardiomyocytes, altering their mitochondrial respiration and calcium handling in vitro. CytoSorb ${ }^{\circledR} 300$ filtration reduced Midkine concentration ex vivo and in vitro depending on the dosage.

Conclusion and Implications: Midkine is elevated in human and porcine plasma after multiple trauma, affecting the functionality and metabolism of human cardiomyocytes in vitro. Further examinations are required to determine whether the application of CytoSorb ${ }^{\circledR} 300$ filtration in patients after multiple trauma is a promising therapeutic approach to prevent post-traumatic cardiac disfunction.

Keywords: polytrauma, cardiac dysfunction, fracture treatment, damage associated molecular pattern, toll-like receptor, toll-like receptor signaling, prevention cardiac injury, CytoSorb ${ }^{\circledR} 300$ 


\section{INTRODUCTION}

According to the World Health Organization (WHO), trauma accounts for $10 \%$ of deaths and $16 \%$ of disabilities worldwide (1). Multiple trauma in humans (Injury Severity Score, ISS $\geq 16$ ) are characterized by a massive release of different inflammatory biomarkers, such as cytokines, and damage associated molecular patterns (DAMPs). This damage affects different organs of the body and can trigger whole-body inflammation after trauma $(2,3)$. A substantial release of these trauma-dependent molecules is associated with the development of the so-called systemic inflammatory response syndrome (SIRS) and the multiple organ dysfunction syndrome (MODS), which are both associated with an increased mortality $(4,5)$. Many of the released inflammatory cytokines and DAMPs were recently shown to be cardiodepressive by acting on cardiomyocytes (CMs), altering their calcium handling, redox balance, signaling transduction, and finally resulting in post-traumatic cardiac dysfunction $(6,7)$. One inflammatory cytokine is the heparin-binding growth- and differentiation factor Midkine (Mdk). Increased Mdk expression is associated with different traumatic conditions such as bone fracture, burn injury, traumatic spinal cord injury, and sepsis (8-11). Increased Mdk in human blood can persist for overall 42 days after fracture (11). Furthermore, Mdk impairs fracture healing by reducing bone formation and increasing neutrophil infiltration during the fracture healing process $(12,13)$. However, the trauma-dependent elevation of Mdk in multiply injured patients as well as the exact impact of Mdk on the heart after trauma remains unclear. In patients with chronic heart failure, circulating Mdk increases significantly and is regarded as a novel marker, predicting different cardiac events $(14,15)$. Moreover, Mdk plays a role in ischemic heart injury, myocardial infarction and cardiac hypertrophy (16-18). Nevertheless, the function of $\mathrm{Mdk}$ in these different pathologies is still controversial, because in some cases such as ischemic heart injury, chronic heart failure and myocardial infarct, Mdk has positive effects by improving cell survival and cardiac function, inducing angiogenesis and reducing detrimental remodeling (17, 19, 20). In contrast, Mdk reduces cellular survival and induces pathological remodeling as well as fibrosis in patients with cardiac hypertrophy (18). Consequently, the exact effect of Mdk on the heart is ambiguous since Mdk can have beneficial and detrimental effects in cardiac pathology. The function of $\mathrm{Mdk}$ as an inflammatory cytokine on the heart during trauma especially requires clarification. After all, Mdk might be a potential therapeutic option in cardiac diseases as well as in the treatment and prevention of post-traumatic cardiac injury $(21,22)$. Mdk has been shown to play an important role in active myocarditis in patients and in experimental autoimmune myocarditis in mice (23). In these instances, Mdk promotes the recruitment of polymorphonuclear neutrophils (PMNs) and the production of neutrophil extracellular traps (NETs) in cardiac tissues, resulting in impaired systolic function (23). Increased activation and recruitment of neutrophils in cardiac tissue were also observed in humans after trauma and in experimental blunt chest trauma models in rats. In addition, it is linked to increased systemic levels of extracellular histones by NETosis, leading to cardiac dysfunction $(24,25)$.

In this study, we investigate the Mdk elevation in blood circulation after multiple trauma in pigs and humans. We further aim to thoroughly examine the effects of Mdk on human CMs. With regards to therapeutic options for posttraumatic cardiac dysfunction, the study aims to investigate the usage of CytoSorb ${ }^{\circledR} 300$ hemadsorption. In clinical settings, CytoSorb ${ }^{\circledR}$ 300 hemadsorption improved the outcome of patients with endotoxemia, necrotizing fasciitis, septic shock, and cardiac surgery (26-29). Furthermore, CytoSorb ${ }^{\circledR}$ hemadsorption resulted in immediate hemodynamic stabilization and increased survival rates in patients with multiple organ failure (30). CytoSorb $^{\circledR} \quad 300$ consists of highly porous (styrene-codivinylbenzene) hemadsorbent polymer beads, which can remove substances within $10-60 \mathrm{kDa}$ of molecular weight, such as complement factor 5a, cytokines DAMPs and pathogen associated molecular patterns (PAMPs), from circulating blood (26, 31). Similarly, the high-mobility group box 1 protein (HMGB1) can be removed from blood in a time dependent manner (31). Lastly, the study examines the capacity of CytoSorb ${ }^{\circledR} 300$ to filtrate Mdk, which may be used as a therapeutic approach for preventing and handling post-traumatic cardiac dysfunction.

\section{MATERIALS AND METHODS}

\section{Human Blood Samples}

Human plasma from 11 multiply injured patients with a history of acute blunt or penetrating trauma and an ISS $\geq$ 16 was collected after hospital admission in the University Hospital of the Goethe-University Frankfurt with institutional ethics committee approval (312/10), in accordance with the Declaration of Helsinki and following the Strengthening the Reporting of Observational studies in Epidemiology (STROBE)guidelines (32). All enrolled patients either signed the written informed consent form or written informed consent was obtained from the nominated legally authorized representative of the participants in accordance with ethical standards. Exclusion criteria were the patients being younger than 18 or older than 80 years, presenting severe burn injury, acute myocardial stroke, cancer or chemotherapy, immunosuppressive drug therapy, HIV, infectious Hepatitis, acute CMV infection, and/or thromboembolic events. Control blood samples were collected from healthy volunteers $(n=6,50: 50$ female male, no comorbidities). Randomization of the groups was not possible during the sample collection. Blood samples were withdrawn in ethylenediaminetetraacetic acid (EDTA) tubes (Sarstedt, Nürmbrecht, Germany) directly after admission. The samples were kept on ice until centrifugation at 2,100 $\mathrm{g}$ for $15 \mathrm{~min}$. Then, the supernatant was collected and stored at $-80^{\circ} \mathrm{C}$ until assay.

\section{Animals}

This study presents partial results obtained from a large animal porcine multiple trauma model, conducted by the TREAT research group. 
The animal housing and experimental protocols were approved by the Cantonal Veterinary Department, Zurich, Switzerland, under license no. ZH 138/2017, and were in accordance with Swiss Animal Protection Law. Housing and experimental procedures also conformed to the European Directive 2010/63/EU of the European Parliament and of the Council on the Protection of vertebrate animals used for scientific purposes (Council of Europe no. 123, Strasbourg 1985) and to the Guide for the Care and Use of Laboratory Animals (Institute of Laboratory Animal Resources, National Research Council, National Academy of Sciences, 2011). Twentyfive male pigs weighting $50 \pm 5 \mathrm{~kg}$ (Sus scrofa domestica) were included in the study (mean height, snout-tail length: $123,6 \mathrm{~cm}$ ). Animals were held in a controlled environment with $21 \pm 3^{\circ} \mathrm{C}$ room temperature (50\% humidity), with a light/dark cycle of $12 \mathrm{~h}$. Water was available for animals ad libitum. General instrumentation, anesthesia and trauma induction were described previously by Horst et al. (33).

\section{Analgesia and Anesthesia}

For premedication, pigs received an intramuscular injection with ketamine (20 $\mathrm{mg} / \mathrm{kg}$ body weight), azaperone (1-2 $\mathrm{mg} / \mathrm{kg}$ body weight) and atropine $(0.1-0.2 \mathrm{mg} / \mathrm{kg}$ body weight). Anesthesia was performed by intravenous application of propofol (2,6-diisopropylphenol) (1-2 $\mathrm{mg} / \mathrm{kg}$ body weight). Anesthesia was maintained during the study period with propofol $(5-10 \mathrm{mg} / \mathrm{kg} / \mathrm{h})$. Pain medication was ensured by sufentanyl $(1 \mu \mathrm{g} / \mathrm{kg} / \mathrm{h})$ perfusion over the whole observation period.

\section{Multiple Trauma in Pigs}

Analgesia and Anesthesia of the animals was maintained during the whole procedure.

Pigs underwent either multiple trauma $(n=20)$ or shamprocedure $(n=5)$. Multiple trauma includes a combination of a penetrating thorax trauma, laparotomy, liver laceration, femur fracture, and hemorrhagic shock (ISS $\geq 27$ ). Control animals underwent sham-procedure $(n=5)$. Femur fracture was induced by a bolt gun (Blitz-Kernen, turbocut JOBB $\mathrm{GmbH}$, Germany), positioned on the mid third of the left femur. The gun was loaded with cattle-killing cartridges $(9 \mathrm{x}$ 17; DynamitNobel AG, Troisdorf, Germany). For introduction of blunt chest trauma, a pair of panels (steel $0.8 \mathrm{~cm}$, lead $1.0 \mathrm{~cm}$ thickness) was placed on the right dorsal lower chest. A shock wave was induced by a bolt shot (Blitz-Kerner, turbocut JOBB GmbH, Germany), which was applied onto the panel using cattle-killing cartridges as previously described $(34,35)$. Midline-laparotomy was performed by exploring the right upper liver lobe. Penetrating hepatic injury was induced by cross-like incision halfway through the liver tissue. After a short period of uncontrolled bleeding (30 s), liver package was performed. Directly after the hepatic package, pressure-controlled and volume-limited hemorrhagic shock was induced by withdrawing blood until a mean arterial pressure (MAP) of $30 \pm 5 \mathrm{~mm} \mathrm{Hg}$ was reached. Maximal withdrawal amounts to $45 \%$ of total blood volume. The reached MAP was maintained for $60 \mathrm{~min}$. At the end of the shock period, animals were resuscitated according to established trauma guidelines (ATLS ${ }^{\circledR}$, AWMF-S3 guideline on Treatment of Patients with Severe and Multiple Injuries ${ }^{\circledR}$ ) by adjusting $\mathrm{FiO}_{2}$ and an initial substitution of the withdrawn blood volume with Ringerfundin, fluid maintenance was performed by continuous infusing additional fluids (Ringerfundin, 2 $\mathrm{ml} / \mathrm{kg}$ body weight/h). Moreover, pigs were rewarmed until normothermia $\left(38.7-39.8^{\circ} \mathrm{C}\right)$ was reached. Sham procedure $(n$ $=5$ ) included instrumentation and anesthesia but without trauma or hemorrhage. The multiple trauma group $(n=20)$ was randomized in four therapy arms: pigs received either femoral nailing without reaming $(n=5)$, standard reaming $(n=5)$, reamed irrigation and aspiration (RIA I) $(n=5)$ or reamed irrigation and aspiration with reduced diameter and improved control of irrigation and suction (RIA II) $(n=5)$. In all groups a shortened conventional tibia nail was introduced.

\section{Follow-Up and Euthanasia}

Hemodynamic parameters were continuously monitored for $6 \mathrm{~h}$. Pigs were euthanized under deep general anesthesia with intravenous Na-Pentobarbital.

This animal model represents a clinically relevant porcine model of severe multiple trauma (pulmonary contusion, extremity injury, liver laceration) with post-traumatic observation period under ICU conditions (33).

\section{Sample Collection}

Serum and plasma samples were collected at baseline, 4 and $6 \mathrm{~h}$ after multiple trauma and kept on ice. After centrifugation $\left(1,500 \mathrm{~g}\right.$ for $12 \mathrm{~min}$ at $\left.4^{\circ} \mathrm{C}\right)$, serum and EDTA-plasma were removed and stored at $-80^{\circ} \mathrm{C}$ until analysis. Heart tissue samples were obtained $6 \mathrm{~h}$ after resuscitation. Tissue of the superficial and the luminal left ventricle was fixed with $4 \%$ formalin, followed by embedding in paraffin. Furthermore, tissue was quick-frozen in liquid nitrogen, followed by storage at $-80^{\circ} \mathrm{C}$ until analysis.

\section{Midkine ELISA}

For determination of Midkine in human and porcine plasma, as well as for the CytoSorb ${ }^{\circledR} 300$ experiments, the human Midkine ELISA (R\&D Systems, McKinley, MN, USA) was used. All procedures were performed according to manufacturers' instructions. Midkine ELISA was performed by a blinded investigator. Human plasma samples were diluted 1:4 and porcine plasma samples were diluted 1:2.

\section{ips-Cardiomyocyte Cell Culture}

Human cardiomyocytes (iPS) (Cellular Dynamics, Madison, WI, USA) were cultured for 10 days in maintenance medium at $37^{\circ} \mathrm{C}$ and in an atmosphere of $7 \% \mathrm{CO}_{2}$, according to manufacturers' recommendations.

\section{Binding Analysis of FITC-Labeled Midkine}

Fluorescein isothiocyanate (FITC) (Sigma Aldrich, St. Louis, $\mathrm{MO}$, USA) was dissolved in DMSO. Two $\mathrm{mg} / \mathrm{ml}$ Midkine (Dianova, Hamburg, Germany), dissolved in $0.1 \mathrm{M} \mathrm{NaHCO}_{3}$ were added to $3 \mathrm{mg} / \mathrm{ml}$ fluorescein isothiocyanate (FITC) (Sigma Aldrich, St. Louis, MO, USA) solution and were incubated for $1 \mathrm{~h}$ at RT while continuously shaking. Unbound FITC was removed 
by using SnakeSkin ${ }^{\circledR}$ dialysis tube (ThermoScientific, Waltham, MA, USA). For dialysis, 1X phosphate buffered saline was used. Human CMs were seeded at a density of $6.3 \times 10^{4}$ cells $/ \mathrm{cm}^{2}$ on ibidi 12-well chamber slides (ibidi, Germany). Afterwards, cells were incubated for 30 and $60 \mathrm{~min}$ with $100 \mathrm{ng} / \mathrm{ml}$ FITClabeled Midkine. Cells were washed, fixed with $4 \%$ formalin and cell nuclei were counterstained using Hoechst (Sigma Aldrich, St. Louis, MO, USA). Cells were mounted with ProLong ${ }^{\circledR}$ Gold Antifade Mountant (ThermoScientific, Waltham, MA, USA). Cells were analyzed by blinded investigator by using Axio Imager M.2 microscope (Zeiss, Jena, Germany) and the Zeiss ZEN 2.3 software (Zeiss, Jena, Germany). Images were performed with 40x magnification (N.A. 0.75).

\section{Cell Viability Assay}

Cell viability was analyzed using Cell Titer-Glo ${ }^{\circledR}$ Luminescent Cell Viability Assay (Promega, Madison, WI, USA). Cells were seeded with a density of $6.3 \times 10^{4}$ cells $/ \mathrm{cm}^{2}$ on a 96-well plate and treated with different Midkine concentrations $(0.05,0.1,1 \mu \mathrm{g} / \mathrm{ml})$ for $3 \mathrm{~h}$, or with $1 \mu \mathrm{g} / \mathrm{ml}$ for different incubation times $(0.5,1$, or $3 \mathrm{~h}$ ). All procedures were performed according to manufacturers' instructions. For all experiments $n=6$.

\section{Troponin I ELISA}

Human CMs were seeded with a density of $6.3 \times 10^{4}$ cells $/ \mathrm{cm}^{2}$ on a 24 -well plate and treated for $6 \mathrm{~h}$ with $100 \mathrm{ng} / \mathrm{ml}$ Midkine at $37^{\circ} \mathrm{C}$ and $7 \% \mathrm{CO}_{2}$. Supernatant was collected and troponin I in supernatant was determined by using Human Cardiac Troponin I ELISA (Abcam, Cambridge, UK). All procedures were performed according to manufacturers' instructions. For all experiments $n=6$.

\section{Caspase-3/7 Assay}

Human cardiomyocytes were seeded with a density of $6.3 \times 10^{4}$ cells $/ \mathrm{cm}^{2}$ on a 96 -well plate and treated with $100 \mathrm{ng} / \mathrm{ml}$ Midkine for $6 \mathrm{~h}$ at $37^{\circ} \mathrm{C}$. Caspase-3/7 activity in human cardiomyocytes was examined by using Caspase-Glo ${ }^{\circledR}$ 3/7 Assay (Promega, Madison, WI, USA). All procedures were performed according to manufacturers' instructions. For all experiments $n=6$.

\section{Live Cell Imaging}

Live cell imaging was performed using Leica Microscope SP8 and LAS X software (Leica, Wetzlar, Germany). Cells were seeded with a density of $6.3 \times 10^{4}$ cells $/ \mathrm{cm}^{2}$ on a 96 -well plate and were pre-loaded with $5 \mu \mathrm{M}$ calcium indicator Fluo-3AM (Life Technologies, Carlsbad, CA, USA) and were incubated for 30 min at $37^{\circ} \mathrm{C}$ and $7 \% \mathrm{CO}_{2}$. After incubation with Fluo-3AM, cells were analyzed immediately. For measurements, cells were placed in special live cell imaging chamber, adjusted at $37^{\circ} \mathrm{C}$ and $7 \% \mathrm{CO}_{2}$. Cells were incubated with $100 \mathrm{ng} / \mathrm{ml} \mathrm{Mdk}$ for $30 \mathrm{~min}$ and calcium signals were recorded and evaluated by using LAS $\mathrm{X}$ software. Cell culture medium was used during measurements. Live cell imaging was performed with $63 \mathrm{x}$ magnification (N.A. 1.2 , water). Calcium peaks were determined and compared to baseline values. For all experiments $n=6$.

\section{Calcium Measurements}

For calcium measurements, human cardiomyocytes (iPS) were seeded with a density of $6.3 \times 10^{4}$ cells $/ \mathrm{cm}^{2}$ on ibidi 8well chambers (ibidi, Germany). Before the measurements, cells were incubated with $100 \mathrm{ng} / \mathrm{ml}$ Midkine $60 \mathrm{~min}$ before the start of the experiments, as well as for the duration of the experiment. For measurement of changes in intracellular $\mathrm{Ca}^{2+}$ concentration, cells were loaded with $5 \mu \mathrm{M}$ Fura-2 (ThermoScientific, Waltham, MA, USA) for $30 \mathrm{~min}$ (in presence of pharmacological compounds if needed). After incubation, cells were washed twice with bath solution (in mM: $140 \mathrm{NaCl} ; 5.4 \mathrm{KCl}$; $\mathrm{MgCl}_{2} ; 1.8 \mathrm{CaCl}_{2} ; 5.5$ Glucose; 5 Hepes; $\mathrm{pH}=7.4$ ). Fluorescence imaging was performed on a Cell Observer inverse microscope (Zeiss, Jena, Germany). Cells were illuminated for $90 \mathrm{~min}$ at a rate of $2 \mathrm{~Hz}$ at each excitation wavelength (340 and $380 \mathrm{~nm}$ ). Images were acquired using MetaFluor (Molecular Devices, Ismaning, Germany). Cells were measured in bath solution using 40x magnification (N.A. 1.3) at room temperature. Fura-2 ratios were calculated with ImageJ and the data obtained were analyzed with the Matlab script PeakCaller (36). For all experiments $n=6$.

\section{RNA Isolation}

For qPCR experiments, human CMs were seeded at a density of $6.3 \times 10^{4}$ cells $/ \mathrm{cm}^{2}$ on a 24-well plate and were treated with $100 \mathrm{ng} / \mathrm{ml}$ Midkine for $6 \mathrm{~h}$ at $37^{\circ} \mathrm{C}$ and $7 \% \mathrm{CO}_{2}$. Cells were lysed with RLY lysis buffer (Meridian Bioscience, Cincinnati, OH, USA), containing $10 \mu \mathrm{l} / \mathrm{ml} \beta$ mercaptoethanol (Sigma Aldrich, St. Louis, MO, USA). RNA isolation from cell lysates was performed by using ISOLATE II RNA Mini Kit (Meridian Bioscience, Cincinnati, OH, USA). Remaining DNA was digested by DNase I (Meridian Bioscience, Cincinnati, OH, USA) for $15 \mathrm{~min}$ at $\mathrm{RT}$ as recommended by the manufacturer.

\section{Reverse Transcribed Quantitative Polymerase Chain Reaction (RT-qPCR)}

The respective RNA samples were reverse transcribed in cDNA using SuperScript ${ }^{\circledR}$ IV VILO ${ }^{\circledR}$ MasterMix (Life Technologies, Carlsbad, CA, USA). For cDNA transcription, $1-5 \mathrm{ng} / \mathrm{ml}$ mRNA were used, and experiment was performed according to manufacturer's instructions. For quantitative PCR, the PowerUp ${ }^{\circledR}$ SYBR ${ }^{\circledR}$ Green Master Mix (Applied Biosystems, Waltham, MA, USA) was used. All procedures were performed according to the manufacturers' instructions. For qPCR, the QuantStudio3 (Applied Biosystems, Waltham, MA, USA) system was utilized. Five-hundred to seven-hundred ng/ml cDNA were used for quantitative PCR. Quantitative mRNA expression of human troponin I (for: 5'-CCTCCAACTACCGCGCGCTTAT-3', rev: 5'-CTGCAATTTTCTCGAGGCGG-3'), sarco/endoplasmic reticulum $\mathrm{Ca}^{2+}$-ATPase (SERCA2a) (for: 5'-CTCCTTGCCCGT GATTCTCA-3', rev: 5'-CCAGTATTGCAGGTTCCAGGT$3^{\prime}$ ), ryanodine receptor 1 (RyR1) (for: 5'-GGGTTCCTGCCC GACATGAG-3', rev: 5'-GCACAGGTAGCGGTTCACG-3'), $\mathrm{Na}^{+} / \mathrm{Ca}^{2+}$ exchanger (NCX) (for: 5'-GCCTGGTGGAGATGAG TGAG-3', rev: 5'-ACAGGTTGGCCAAACAGGTA-3'), toll-like receptor 4 (TLR4) (for: 5'-CCTGCGTGGAGGTGTGAAAT-3', rev: 5'-CTGGATGGGGTTTCCTGTCAA-3'), toll-like receptor 9 (TLR9) (for: 5'-AGACCTGAGGGTGGAAGTGT-3', rev: 


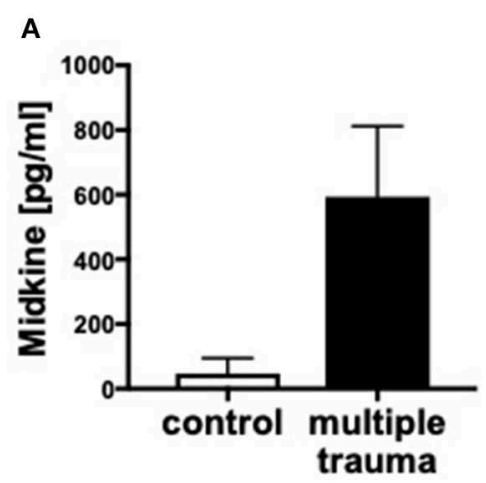

B

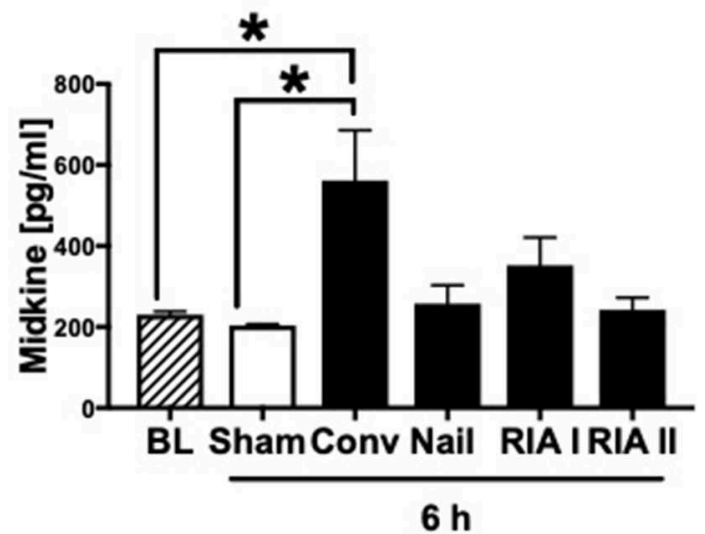

FIGURE 1 | Midkine levels in blood plasma of multiply injured humans and pigs. Midkine levels $(\mathrm{pg} / \mathrm{ml}$ ) in shock room blood plasma from multiply injured patients compared to healthy control group $(n=10)$ (A). Midkine levels $(\mathrm{pg} / \mathrm{ml})$ in blood plasma of multiply injured pigs (B). The pigs' femur fracture was either treated with femoral nailing (nailing, $n=5$ ), conventional (conv, $n=5$ ), or with reamer irrigator aspirator 1 or 2 (RIA I or RIA II, each $n=5)$. Control animals received sham-procedure $(n=5)$. Evaluation of blood plasma at baseline $(\mathrm{BL})$ and $6 \mathrm{~h}$ after trauma. Results are presented as mean $\pm \mathrm{SEM}$. Data were analyzed by one-way ANOVA followed by Dunnett's or Tukey's multiple comparison test. Results are significant ${ }^{*} p<0.05$

$5^{\prime}$-CTGGATAGCACCAGTAGCGG-3') and purigenic receptor subtype 7 (P2X7) (for: 5'-CACACCAAGGTGAAGGGGAT-3', rev: $5^{\prime}$-GGTGTAGTCTGCGGTGTCAA-3') was examined and calculated by the cycle threshold method $\Delta \Delta \mathrm{Ct}$. Respective genes were normalized to expression of the housekeeping gene glutaraldehyde-phosphate dehydrogenase (GAPDH) (forward: 5'-TCTCTGCTCCTCCTGTTCGAC-3', reverse: 5'-CCAA TACGACCAAATCCGTTGA-3') in order to exclude variations. Quantitative mRNA expression was determined by the doublethreshold method $(\Delta \Delta \mathrm{CT})$. Results are presented as mean fold change. For all experiments $n=6$.

\section{Reactive Oxygen Species (ROS)}

For analysis of cellular ROS, human CMs were seeded at a density of $6.3 \times 10^{4}$ cells $/ \mathrm{cm}^{2}$ on ibidi 12 -well slides (ibidi, Germany). Human CMs were treated with $100 \mathrm{ng} / \mathrm{ml}$ Midkine for $6 \mathrm{~h}$ at $37^{\circ} \mathrm{C}$ and $7 \% \mathrm{CO}_{2}$. After treatment, cells were incubated for another $30 \mathrm{~min}$ with $5 \mu \mathrm{M}$ CellROX ${ }^{\circledR}$ Deep Red Reagent (Life Technologies, Carlsbad, CA, USA) at $37^{\circ} \mathrm{C}$ and $7 \% \mathrm{CO}_{2}$. Afterwards, cells were fixed with $4 \%$ formaldehyde and cell nuclei were stained with Hoechst. Cell were mounted with ProLong ${ }^{\circledR}$ Gold Antifade Mountant. Cells were investigated by blinded investigator by fluorescence microscopy using Axio Imager M.2 microscope and the Zeiss ZEN 2.3 software. Imaging was performed by using 20x magnification (N.A. 0.5). Relative amount of reactive oxygen species was determined by Zeiss ZEN 2.3 software in order to exclude variations. For all experiments $n=6$.

\section{Mitochondrial Respiration With Seahorse XF Analyzer}

Mitochondrial respiration was analyzed by using the Seahorse XFe96 Analyzer (Agilent Technologies, Santa Clara, CA, USA). This extracellular flux analyzer makes it possible to perform highly accurate real-time measurements of cellular metabolism in living cells by simultaneously quantifying the rates of extracellular acidification (ECAR) and oxygen consumption (OCR), and measuring the glycolysis and the mitochondrial respiration of the cells. For the analysis of mitochondrial respiration, the Seahorse XF Cell Mito Stress Test Kit (Agilent Technologies, Santa Clara, CA, USA) was used. The Seahorse XF Cell Mito Stress Test Kit is an optimized solution for assessing mitochondrial function. During the experiment, the ECAR and the OCR were continuously measured, gaining the parameter for the basal (baseline) respiration of the mitochondria. Afterwards, $2 \mu \mathrm{M}$ oligomycin, $1 \mu \mathrm{M}$ carbonyl cyanide 4-(trifluoromethoxy) phenylhydrazone (FCCP), and $0.5 \mu \mathrm{M}$ antimycin A and rotenone were pneumatically injected into the media of the cells. After automatically and gently mixing, the OCR and the ECAR were measured at multiple times after each injection. After the experiment, cells were fixed with $4 \%$ formalin at $4{ }^{\circ} \mathrm{C}$ overnight. Then, cells were stained with $0.3 \%$ Janus-Green solution (Sigma Aldrich, St. Louis, MO, USA), washed and resolved with $0.5 \mathrm{M}$ hydrochloric acid. Optical density was measured at $630 \mathrm{~nm}$ and OCR values were normalized to OD $630 \mathrm{~nm}$ values to exclude variations. Results were evaluated using Seahorse Wave 2.4 software (Agilent Technologies, Santa Clara, CA, USA), gaining the parameter for spare respiratory capacity of the mitochondria. For the analysis of mitochondrial respiration, cells were seeded with a density of $5 \times 10^{5}$ cells $/ \mathrm{cm}^{2}$ on Seahorse XFe96 analyzer cell culture plates (Agilent Technologies, Santa Clara, CA, USA) and incubated for $6 \mathrm{~h}$ with $100 \mathrm{ng} / \mathrm{ml}$ Midkine and the above- mentioned procedure was performed. For all experiments $n=6$.

\section{CytoSorb $^{\circledR} 300$ Experiments}

For the therapeutic experiments, the CytoSorb ${ }^{\circledR} 300$ was used (CytosorbensInc., MonmouthJunction, NJ, USA). Therefore, small columns were prepared. An excess of CytoSorb ${ }^{\circledR} 300$ at the ratio 2:1 (CytoSorb ${ }^{\circledR} 300$ to plasma samples) was added on the column as recommended by the manufacturers. Human shock room blood plasma samples were added on the columns and were 
A

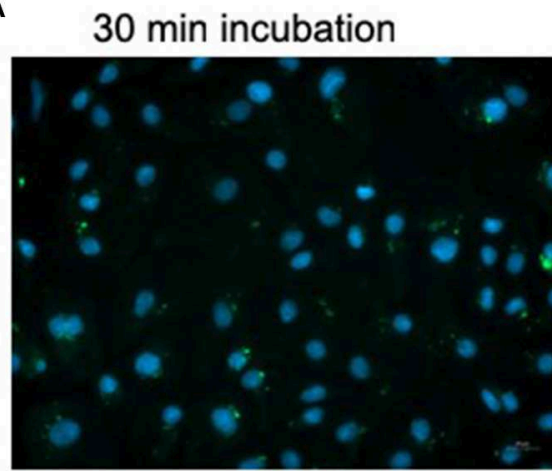

B

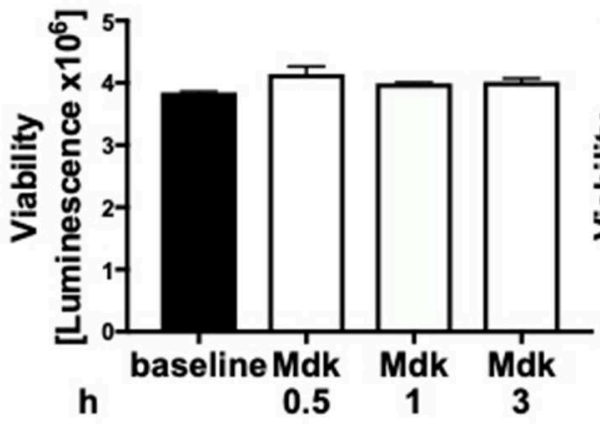

60 min incubation

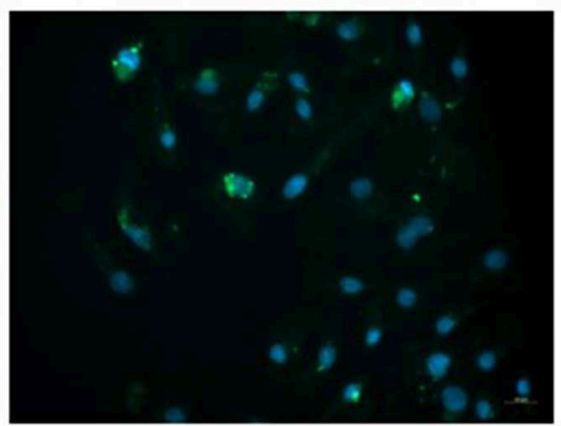

C

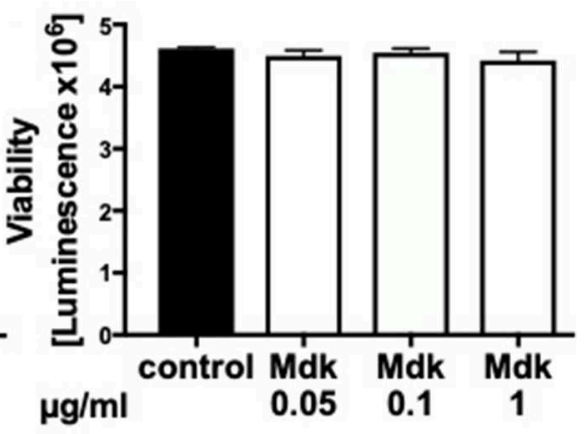

D

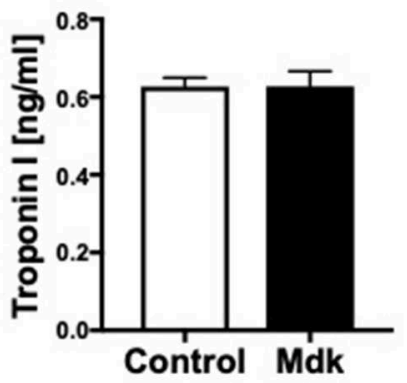

FIGURE 2 | Effects of Midkine on human cardiomyocytes. Immunofluorescence staining of human cardiomyocytes (A). Human cardiomyocytes were treated for 30 and $60 \mathrm{~min}$ with $100 \mathrm{ng} / \mathrm{ml}$ fluorescein isothiocyanate (FITC)-labeled Midkine (green). Cell nuclei were counterstained with Hoechst (blue). Cell viability of human cardiomyocytes (Luminescence in counts/sec) treated for 0.5, 1, and $3 \mathrm{~h}$ with $100 \mathrm{ng} / \mathrm{ml}$ Midkine (B). Cell viability of human cardiomyocytes (Luminescence in counts/sec) treated for $3 \mathrm{~h}$ with $0.05,0.1$, and $1 \mu \mathrm{g} / \mathrm{ml}$ Midkine (C). Troponin I (ng/ml) in supernatant of human cardiomyocytes, treated for $6 \mathrm{~h}$ with $100 \mathrm{ng} / \mathrm{ml}$ Midkine (D). Results are presented as mean \pm SEM. For all experiments $n=6$. Data were analyzed by two-tailed, unpaired students $t$-test.

incubated for 6 or $3 \mathrm{~h}$ at RT while continuously shaking. For timedoses experiments, different Midkine concentrations (10,000, $5,000,2,500,2,000,1,500,1,000,500,1,000 \mathrm{pg} / \mathrm{ml})$ diluted in PBS with $1 \%$ BSA were added on the columns and were also incubated for 6 and $3 \mathrm{~h}$ at RT, while continuously shaking. For all experiments $n=6$.

\section{Statistical Analysis}

All values were expressed as means \pm SEM. Data were analyzed by one-way ANOVA followed by Dunnett's or Tukey's multiple comparison test. For the statistical analysis of two groups, unpaired two-tailed students $t$-test was used. $p \leq 0.05$ was considered statistically significant. GraphPad Prism 7.0 software was used for statistical analysis (GraphPad Software, Incorporated, San Diego, CA, USA).

\section{RESULTS}

\section{Midkine Plasma Levels in Multiply Injured Humans and Pigs}

In humans as well as in pigs, the blood plasma concentrations of Midkine increased after multiple trauma compared to the healthy controls (Figures 1A,B). Animals submitted to 


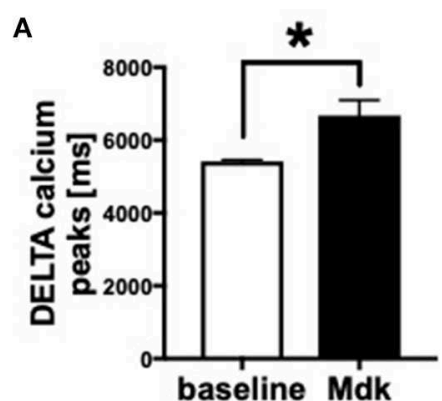

C

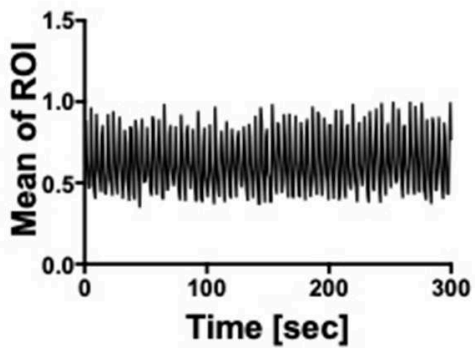

E

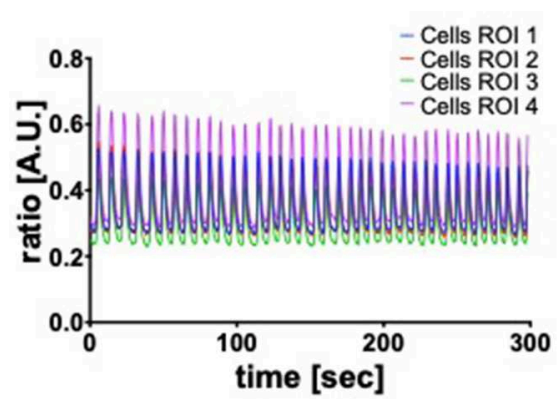

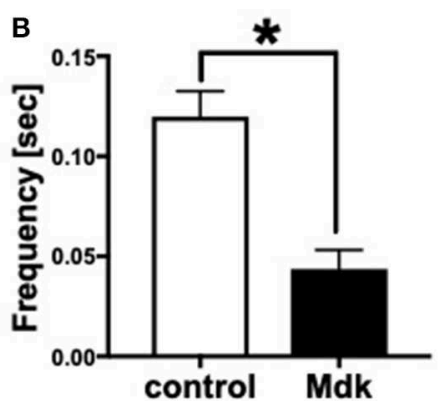

D

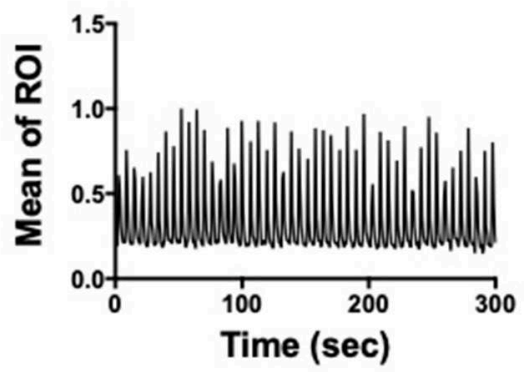

$\mathbf{F}$

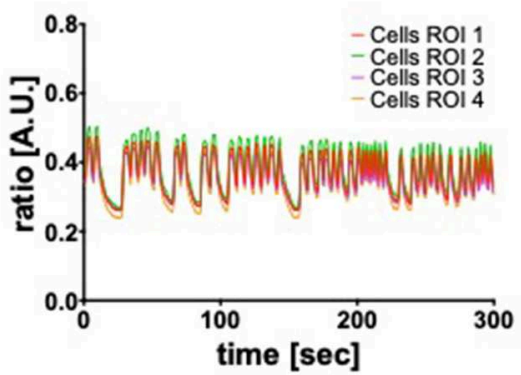

FIGURE 3 | Calcium handling of human cardiomyocytes. Delta calcium peaks (msec) of human cardiomyocytes treated for $30 \mathrm{~min}$ with $100 \mathrm{ng} / \mathrm{ml}$ Midkine (A). Frequency of calcium signals (sec) of human cardiomyocytes treated for $60 \mathrm{~min}$ with $100 \mathrm{ng} / \mathrm{ml}$ Midkine (B). Traces of calcium signals of human cardiomyocytes (Mean Calcium peaks of ration of interest (ROI) vs. time in sec) $\mathbf{( C , D ) . ~ T r a c e s ~ o f ~ c a l c i u m ~ s i g n a l s ~ o f ~ h u m a n ~ c a r d i o m y o c y t e s ~ ( R a t i o ~ o f ~ F u r a - 2 ~ s i g n a l s ~ i n ~ A . U . ~ v s . ~ t i m e ~ i n ~ s e c ) ~}$ (E,F). Different colors for selected ROI of calcium signals of the cells. For all experiments $n=6$. Results are presented as mean \pm SEM. Data were analyzed by one-way ANOVA followed by Dunnett's or Tukey's multiple comparison test. Results are significant ${ }^{*} p<0.05$.

reamed femoral nailing showed significantly higher Mdk levels when compared with pigs treated with conventional femoral nailing or with reamer irrigator aspirator treatment (RIA I/II; Figure 1B). This indicates that Mdk levels correlate with the invasiveness of the reaming method. In multiply injured pigs, plasma Mdk levels increased significantly after $6 \mathrm{~h}$ in the group with conventional reaming of the fracture compared to the control group.

Since plasma Mdk levels increased after multiple trauma, we investigated whether Mdk affects human cardiomyocytes (CMs). After 30 and $60 \mathrm{~min}$ the Mdk was actively absorbed into the human $\mathrm{CMs}$ and was primarily located around their nucleus in vitro (Figure 2A).

\section{Cell Viability, Cell Damage, and Calcium Handling of Human Cardiomyocytes}

Given that Mdk is actively taken into the cells, we examined whether it then affects the cell viability of the human CMs. The cell viability of the human CMs was neither affected by different Mdk concentrations nor by different incubation times (Figures 2B,C). Furthermore, there were no differences in troponin I concentrations in supernatant of the humans CMs treated with Mdk compared to control cells after $6 \mathrm{~h}$ (Figure 2D). However, the calcium handling of the human CMs was altered after Mdk treatment, which is exemplified by the significant increase in their delta calcium peaks (Figure 3A), meaning the cells beat slower in presence of Mdk. Moreover, the frequency of calcium signals 
in human CMs decreased significantly in presence of Mdk, developing bradycardic conditions (Figure 3B), which is also demonstrated the traces of the calcium signals of the cells (Figures 3C-F).

\section{Gene Expression of Human Cardiomyocytes}

We showed that Mdk alters the calcium handling in human CMs. Next, we investigated the gene expression of specific cardiac calcium pumps as well as the expression of different receptors, which might be involved in Mdk signaling. In human CMs, the mRNA expression of SERCA2a, NCX, TLR4, TLR9, and P2X7 increased significantly in presence of $\mathrm{Mdk}$ compared to control (Figures 4A,C-F), indicating for direct effects of Mdk on gene expression of calcium handling proteins. Moreover, the effects of Mdk might be mediated via TLR-P2X7 signaling. The mRNA expression of $R y R 1$ was unaffected (Figure 4B).

\section{Mitochondrial Respiration of Human Cardiomyocytes}

In addition, we analyzed the effects of Mdk on the mitochondrial respiration of CMs Figure 5A. The basal respiration as well as the spare respiratory capacity of the human CMs decreased significantly after the Mdk treatment (Figures 5B,C), indicating detrimental effects of $\mathrm{Mdk}$ on mitochondrial respiration.

\section{Intracellular Reactive Oxygen Species (ROS) and Caspase3/7 Activity}

As Mdk alters mitochondrial respiration and ATP production of the cells, we next investigated whether Mdk also affects the redox balance of the human CMs. The amount of ROS did not change in human CMs after being treated with Mdk compared to control cells (Figure 5D). Although Caspase 3/7 activity increased significantly in human CMs in presence of Mdk (Figure 5E), indicating for enhanced apoptosis in the cells.

\section{Filtration of Midkine by CytoSorb ${ }^{\circledR} \mathbf{3 0 0}$}

Because Mdk is elevated in plasma of multiply injured humans and pigs and acts on human CMs, we examined the potential of a therapeutic approach: the absorption capacity of Mdk from human blood by CytoSorb ${ }^{\circledR}$ 300. After incubation of different Mdk concentrations with CytoSorb ${ }^{\circledR}$ 300, the Mdk levels decreased between 45 and 95\% within $6 \mathrm{~h}$ (Figure 6A). Especially high Mdk concentrations $(10,000 \mathrm{pg} / \mathrm{ml})$ were significantly reduced up to $95 \%$ after filtration with CytoSorb ${ }^{\circledR} 300$ after $6 \mathrm{~h}$ compared to the $3 \mathrm{~h}$ incubation (Figure 6A). Moreover, Mdk levels in plasma from multiply injured patients were significantly reduced after incubation with CytoSorb $^{\circledR} 300$ (Figure 6B).

\section{DISCUSSION}

Our study shows for the first time that Mdk is elevated in blood circulation after multiple trauma. This elevation is similar to other traumatic injuries, suggesting that circulating $\mathrm{Mdk}$ may act as a novel inflammatory marker for polytrauma (8, 9, 11). Furthermore, we demonstrated that Mdk acts directly on

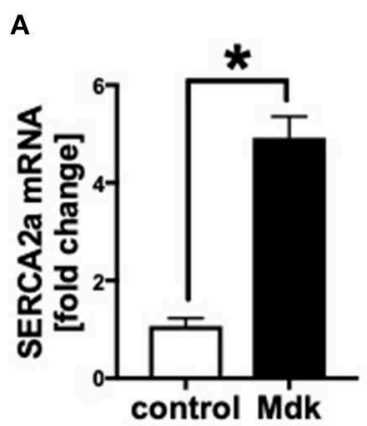

B

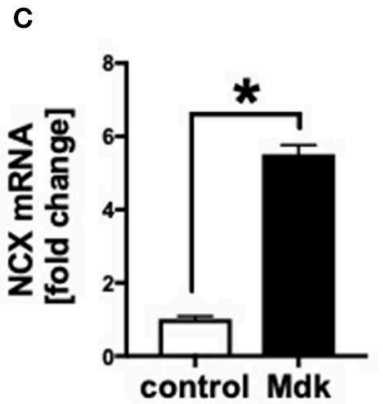

D
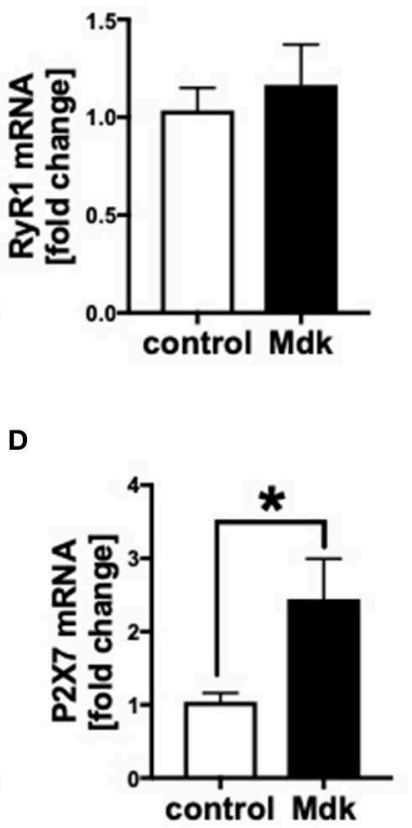

E

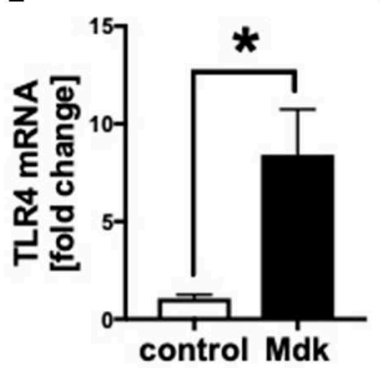

$\mathbf{F}$

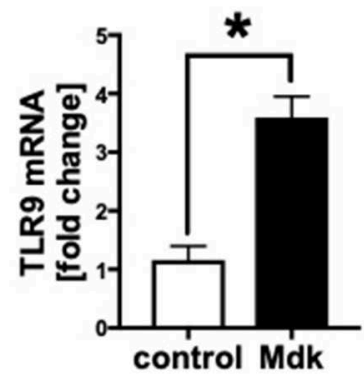

FIGURE 4 | Gene expression of human cardiomyocytes treated for $6 \mathrm{~h}$ with $100 \mathrm{ng} / \mathrm{ml}$ Midkine. mRNA expression (in fold change) of sarco/endoplasmatic reticulum $\mathrm{Ca}^{2+}$-ATPase (SERCA2a) (A), ryanodine receptor-1 (RyR1) (B), sodium-calcium exchanger (NCX) (C), purigenic $P 2 X$ receptor subtype 7 (P2X7) (D), toll-like receptor 4 (TLR4) (E), toll-like receptor 9 (TLR9) (F). Results are presented as mean \pm SEM. Data were analyzed by two-tailed, unpaired students $t$-test. For all experiments $n=6$. Results are significant ${ }^{*} p<0.05$.

human cardiomyocytes in vitro and is actively taken up by these cells, altering their functionality without affecting their viability. We found that Mdk affects the functionality of the human CMs by altering their calcium handling. The delta calcium peaks of the human CMs increased significantly after Mdk treatment, meaning the cells became bradycardic. Moreover, the frequency of the calcium signals in human CMs decreased significantly after Mdk treatment, confirming the bradycardic effect of Mdk. The mRNA expression of the specific cardiac calcium pumps SERCA2a and NCX also increased significantly after Mdk treatment, suggesting direct effects of Mdk on calcium handling in the cells. The location of Mdk around the cell nucleus 
A

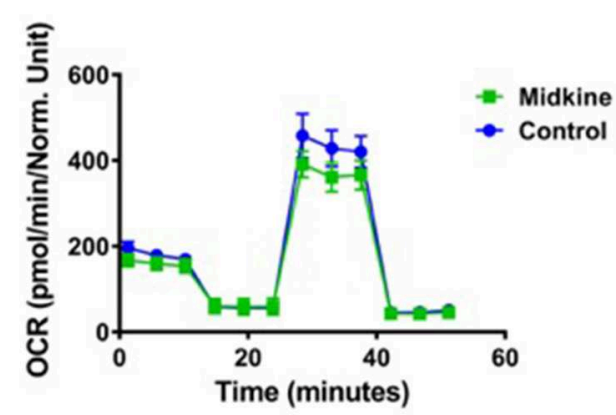

B

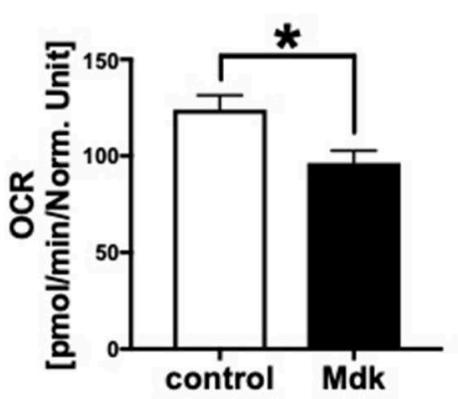

C

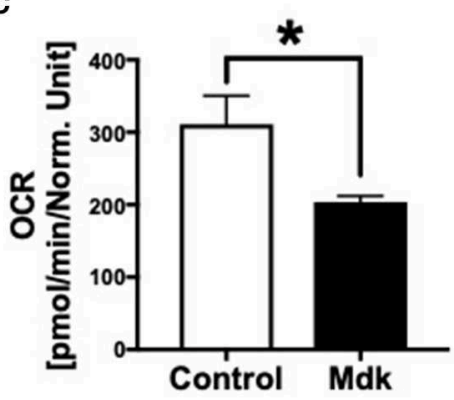

E

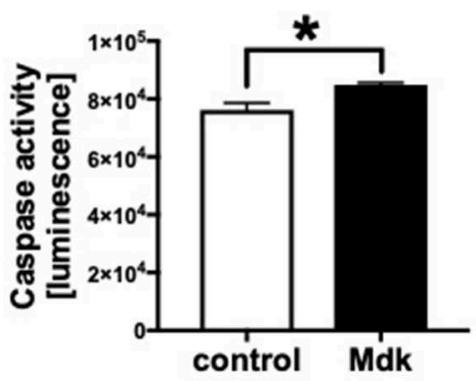

D

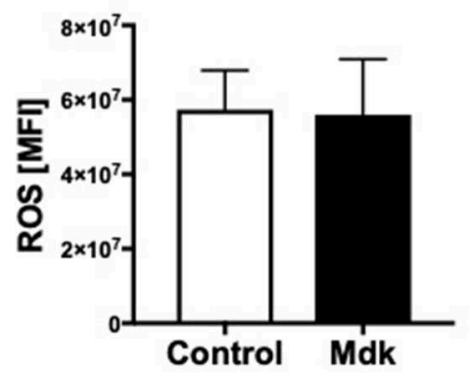

FIGURE 5 | Mitochondrial respiration, cellular reactive oxygen species (ROS) and Caspase 3/7 activity of human cardiomyocytes treated for $6 \mathrm{~h}$ with $100 \mathrm{ng} / \mathrm{ml}$ Midkine. Oxygen consumption rate (OCR) of human cardiomyocytes (Control, Midkine) during Seahorse MitoStress Assay (OCR in pmol/min/E630 vs. time in min) (A). Basal respiration of human cardiomyocytes (OCR in pmol/min/E630) (B). Spare respiratory capacity of human cardiomyocytes (OCR in pmol/min/E630) (C). Amount of reactive oxygen species (mean fluorescence intensity, MFI) (D). Caspase 3/7 activity (Luminescence in counts/sec) (E). Results are presented as mean \pm SEM. For all experiments $n=6$. Data were analyzed by two-tailed, unpaired students $t$-test. Results are significant ${ }^{*} p<0.05$.

of the human CMs confirmed the regulatory effects on cellular gene expression of the calcium handling proteins. Alterations in calcium signals as well as in mRNA expression of SERCA2a and NCX were also described previously in presence of other trauma-related inflammatory biomarkers and DAMPs as well as in different trauma models and during sepsis, nominating Mdk as a powerful cardio-depressive mediator after trauma and during sepsis (25, 37-42). However, cardiac overexpression of SERCA2a in rodents improved cardiac contractility and relaxation, which might also indicate potential protective effects of $\mathrm{Mdk}$ in the heart, which would require to be investigated in future studies $(43,44)$. We also novelly showed that the basal respiration as well as the spare respiratory capacity of the mitochondria of the human CMs decreased significantly, indicating detrimental effects of Mdk on cellular mitochondrial respiration and energy production. Nevertheless, the amount of cytosolic reactive oxygen species (ROS) was not altered in the human CMs in presence of Mdk. Mitochondrial dysfunction was also depicted previously for other trauma-related biomarkers $(7,45,46)$. The detrimental and cardio-depressive effects of Mdk on the human CMs might be mediated via the toll-like receptor (TLR) 4, TLR9, and the pyrogenic receptor subtype 7 (P2X7) since the mRNA expression of these receptors was significantly upregulated. All of these receptors have been demonstrated to be involved in the DAMP-associated cardiac signaling pathways in different trauma models $(47,48)$. The activation of the TLRs results in increased cardiac inflammation, mediated via the nuclear factor $\kappa \mathrm{B}(\mathrm{NF \kappa} \mathrm{B})$ (47). This TLR-mediated cardiac 
A

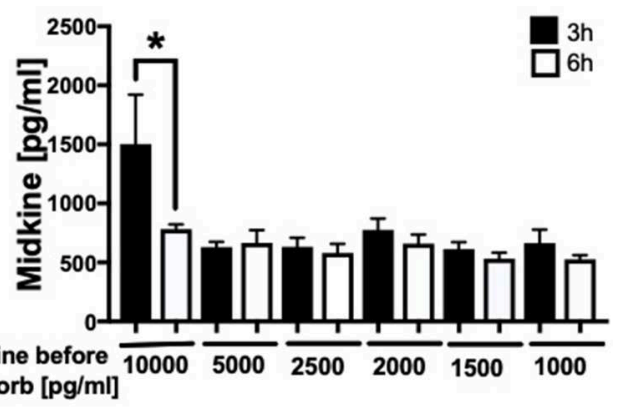

B

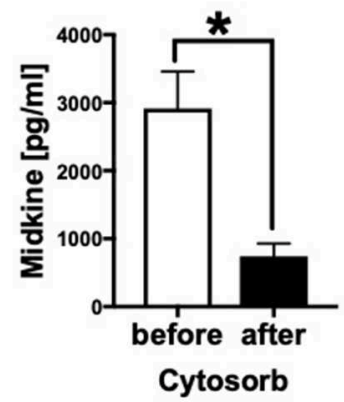

FIGURE 6 | Filtration of Midkine by CytoSorb ${ }^{\circledR} 300$. Filtration of different Midkine concentrations (10,000, 5,000, 2,500, 2,000, 1,500, 1,000 pg/ml) (n $=6$ ) with CytoSorb ${ }^{\circledR} 300$ after $3 \mathrm{~h}$ (black bars) and $6 \mathrm{~h}$ (white bars) (A). Midkine concentration before and after filtration with CytoSorb ${ }^{\circledR} 300$ on the $\mathrm{x}$-axis in $\mathrm{pg} / \mathrm{ml}$. Midkine levels $(\mathrm{pg} / \mathrm{ml})$ in human shock room blood plasma of multiply injured patients before and after filtration with CytoSorb ${ }^{\circledR} 300(n=11)$ (B). Results are presented as mean \pm SEM. Data were analyzed by one-way ANOVA followed by Dunnett's or Tukey's multiple comparison test. Results are significant ${ }^{*} p<0.05$. inflammation leads to cardiac injury and finally results in cardiac contractile dysfunction (47-49). Since the mRNA expression of the TLRs was upregulated, the protein expression of these receptors might be increased after Mdk treatment. This might lead to sensitization of the CMs for other systemic circulating DAMPs, such as HMGB1 and extracellular histones, which were elevated after polytrauma, leading to cardiomyocyte dysfunction $(7,24,50)$. The P2X7 receptor was also shown to be involved in cardiac contractile dysfunction (51). Interestingly, the Caspase 3/7 activity increased in human CMs after treatment with Mdk, which was demonstrated previously in cardiac tissue in vivo in an experimental polytrauma model in pigs (41). So far, Mdk was described as an anti-apoptotic factor by decreasing caspase activity in other cells, such as neurons and HepG2 cells, which is in accordance to unaffected cell viability in the present study $(52,53)$. The effects of Mdk on cellular apoptosis of human CMs has not been described, so far. In contrast to other cells, human CMs seem to follow different cellular processes and various signal cascades might be involved in Caspase-3/7 activation and activity when these cells were treated with Mdk. Moreover, this phenomenon could also be time-dependent as we solely investigated the Caspase-3/7 activity after $6 \mathrm{~h}$ of Mdk exposure. This observation should be the subject of future studies in

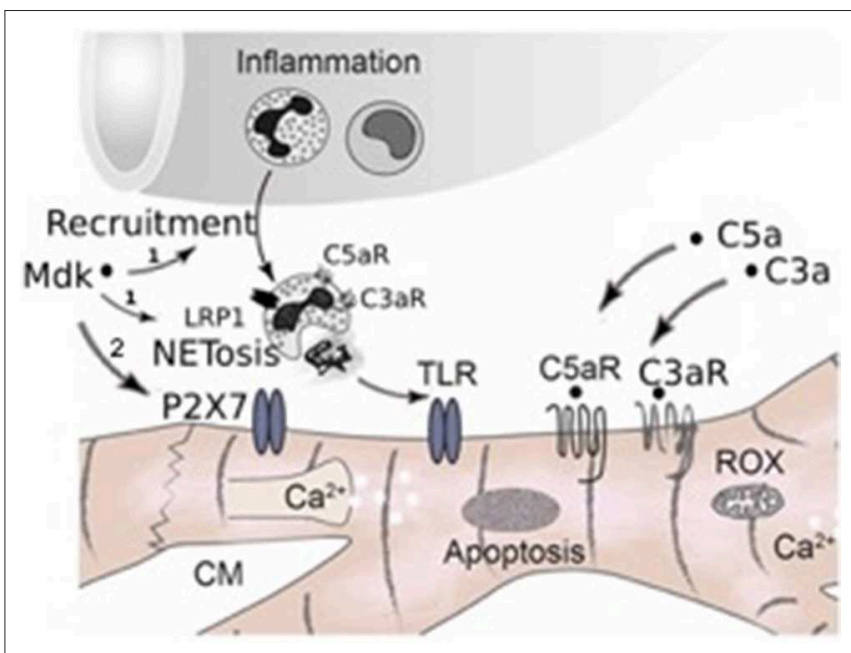

FIGURE 7 | Schematic representation of systemic inflammation after trauma and during sepsis. After trauma Midkine is released systemically. Midkine recruits polymorphonuclear neutrophils (PMNs) and induces the release of extracellular traps (NETosis) via the receptor-related protein 1 (LRP1) on the neutrophils, which was demonstrated by Weckbach et al. (23), (1). The neutrophil extracellular traps (NETs) include extracellular histones, which act via toll-like receptors (TLRs) on the surface of cardiomyocytes, inducing cardiac dysfunction and cardiac damage. Furthermore, Midkine is able to act detrimental on human cardiomyocytes by direct interactions via TLR4, TLR9, and pyrogenic receptor subtype 7 (P2X7), inducing enhanced apoptosis, disturbing calcium signaling and impairing mitochondrial respiration (2, Hypothesis of this manuscript). Additionally, after trauma and during sepsis the complement factors C5a and C3a are released systemically. Both act directly via their receptors (C5aR, C3aR) on cardiomyocytes, leading to cardiac dysfunction. Moreover, the complement factors also induce NETosis of neutrophils via their receptors.

order to understand the specific effects of Mdk on apoptosis of human CMs.

Therapeutic approaches treating post-traumatic cardiac dysfunction are still limited. In this study, we clearly showed that $\mathrm{Mdk}$ is elevated in plasma after multiple trauma and is predominantly detrimental on human CMs, causing the development of post-traumatic cardiac dysfunction. As a consequence, we investigated the efficiency of CytoSorb ${ }^{\circledR} 300$ in filtering Mdk from human blood plasma. CytoSorb ${ }^{\circledR} 300$ is an absorption column, composed of porous polymer beads, which is normally used in the intensive care unit (ICU) for septic patients or for patients with SIRS. The filtration potential of CytoSorb ${ }^{\circledR}$ 300 for various trauma-associated cytokines and DAMPs was already demonstrated by others $(31,54)$. Here, we showed for the first time that CytoSorb ${ }^{\circledR} 300$ is able to absorb Mdk dose-dependently, filtering high Mdk concentrations (10,000 $\mathrm{pg} / \mathrm{ml}$ ) up to $95 \%$. Moreover, CytoSorb ${ }^{\circledR} 300$ filtered Mdk from human plasma obtained on admission to the emergency room, making it a very promising therapeutic approach for treatment and prevention of post-traumatic cardiac dysfunction. One huge benefit of using CytoSorb ${ }^{\circledR} 300$ instead of single antibodies for therapy is that CytoSorb ${ }^{\circledR} 300$ is able to filter a high amount of many miscellaneous damage- and inflammation 
molecules after trauma and not only a single molecule, which is the case of antibody treatment. Furthermore, filtration of Mdk by CytoSorb ${ }^{\circledR} 300$ might limit other negative effects of Mdk on polytrauma patients, since it was shown that Mdk acts as an inhibitor of fracture healing and that high Mdk serum levels were associated with poor outcome in septic patients. Finally, we found that systemic Mdk is higher after conventional reaming, compared to nailing without reaming and to RIA I/II. Consequently, treatment of the fracture with RIA I/II might be better for fracture outcome as well as for fracture healing after trauma (55). In addition, conventional reaming of the fracture might have other negative effects after trauma (e.g., pulmonary embolism).

One limitation of the study might be the small sample size $(n=6)$ to investigate different treatment approaches for the femur fracture. Consequently, more experiments are needed to find the best and the least invasive treatment approach. The same applies for a possible correlation between fracture treatment approaches and systemic Mdk levels. Because investigated groups were heterogenous, a bigger number of samples might be helpful to extrapolate the results to a clinical population. Another limitation might be that we only used small columns with Cytosorb $^{\circledR} 300$ polymer beads in our study, trying to mimic the clinical application in ICU. However, as our study was only an experimental approach, clinical studies should be performed, including more patients and larger application approaches of Cytosorb $^{\circledR}$ 300. This may help to- confirm the therapeutic potential of Cytosorb ${ }^{\circledR} 300$ for the prevention of post-traumatic cardiac dysfunction by filtering Mdk from human blood in vivo. Furthermore, it is not possible to mimic in vitro the real in vivo inflammatory conditions, which occur after trauma. The presence of many different inflammatory mediators and DAMPs and the activation of different signal cascades in the cells lead to post-traumatic cardiac dysfunction. Consequently, it is not possible to specify these detrimental effects on one single mediator like Mdk.

Taken together, in our study we observed for the first time that Mdk is elevated systemically after multiple trauma in humans and pigs, acting cardio-depressive on human CMs by impairing their calcium handling and mitochondrial respiration capacity in vitro. PlX27/TLR might be involved in mediating these detrimental effects of MdK (Figure 7). In the clinical setting, the hemadsorption filter Cytosorb ${ }^{\circledR} 300$ might be a powerful tool to remove cardio-depressive mediators from patients' circulation and therefore help to improve cardiac function.

\section{DATA AVAILABILITY}

All datasets generated for this study are included in the manuscript and/or the supplementary files.

\section{ETHICS STATEMENT}

Human plasma from 11 multiply injured patients with a history of acute blunt or penetrating trauma and an ISS $\geq$
16 was collected after hospital admission in the University Hospital of the Goethe-University Frankfurt with institutional ethics committee approval (312/10), in accordance with the Declaration of Helsinki and following the Strengthening the Reporting of Observational studies in Epidemiology (STROBE)-guidelines (32). All enrolled patients signed the written informed consent form themselves or written informed consent was obtained from the nominated legally authorized representative on the behalf of participants in accordance with ethical standards.

The animal housing and experimental protocols were approved by the Cantonal Veterinary Department, Zurich, Switzerland, under license no. ZH 138/2017, and were in accordance with Swiss Animal Protection Law. Housing and experimental procedures also conformed to the European Directive 2010/63/EU of the European Parliament and of the Council on the Protection of vertebrate animals used for scientific purposes (Council of Europe no. 123, Strasbourg 1985) and to the Guide for the Care and Use of Laboratory Animals (Institute of Laboratory Animal Resources, National Research Council, National Academy of Sciences, 2011).

\section{AUTHOR CONTRIBUTIONS}

IL, BW, MB, TE, GF, SH, ML, and NC performed the experiments including animal studies, cell culture experiments, microscopic studies, and ELISAs. IL primarily wrote the paper. MH-L, FG, $\mathrm{BR}, \mathrm{IM}, \mathrm{RP}, \mathrm{H}-\mathrm{CP}$, and MK contributed to experimental design and data analysis and coordinated the study and supervised financial support for the studies. All authors made substantial contributions to conception and design of the study, participated in drafting the article, and gave final approval of the version to be published.

\section{FUNDING}

This work was conducted in the framework of the CRC 1149 funded by the Deutsche Forschungsgemeinschaft (DFG, German Research Foundation)_Project number 251293561. This work was also funded by the AO Grant S-16-133T: Effects of standard reaming and RIA techniques on local soft tissue and systemic homeostasis in a porcine trauma model.

\section{ACKNOWLEDGMENTS}

We kindly acknowledge the Department of Children and Adolescent Medicine, Division of Pediatric Endocrinology and Diabetes for the provision of the Agilent Seahorse XFe96 analyzer. Thanks to all members of the TREAT research group.

\section{TREAT RESEARCH GROUP}

Auner B, Stormann P, Simon TP, Marx G, Haug A, Egerer L, Giensven MV, Huber-Lang M, Tolba R, Reiss K, Uhlig S, Horst K, Teuben M, Almahoud K, Kalbas Y, Luken H, Almahoud K, and Hildebrand F. 


\section{REFERENCES}

1. WHO. Global Health Estimates 2015 Summary Tables: Deaths by Cause, Age and Sex, 2000-2015 [Online]. Available online at: http://www.who.int/ healthinfo/global_burden_disease?GHE2015_Deaths_Global_2000_2015. xls?ua=1 (2016) (accessed October 1, 2017).

2. Sapan HB, Paturusi I, Jusuf I, Patellongi I, Massi MN, Pusponegoro AD, et al. Pattern of cytokine (IL-6 and IL-10) level as inflammation and antiinflammation mediator of multiple organ dysfunction syndrome (MODS) in polytrauma. Int J Burns Trauma. (2016) 6:37-43.

3. Timmermans K, Kox M, Scheffer GJ, Pickkers P. Danger in the intensive care unit: damps in critically ill patients. Shock. (2016) 45:108-16. doi: 10.1097/SHK.0000000000000506

4. Dewar D, Moore FA, Moore EE, Balogh Z. Postinjury multiple organ failure. Injury. (2009) 40:912-8. doi: 10.1016/j.injury.2009.05.024

5. Guisasola MC, Alonso B, Bravo B, Vaquero J, Chana F. An overview of cytokines and heat shock response in polytraumatized patients. Cell Stress Chaperones. (2018) 23:483-9. doi: 10.1007/s12192-017-0859-9

6. Kumar A, Thota V, Dee L, Olson J, Uretz E, Parrillo JE. Tumor necrosis factor alpha and interleukin 1beta are responsible for in vitro myocardial cell depression induced by human septic shock serum. J Exp Med. (1996) 183:949-58. doi: 10.1084/jem.183.3.949

7. Kalbitz M, Grailer JJ, Fattahi F, Jajou L, Herron TJ, Campbell KF, et al. Role of extracellular histones in the cardiomyopathy of sepsis. FASEB J. (2015) 29:2185-93. doi: 10.1096/fj.14-268730

8. Iwashita N, Muramatsu H, Toriyama K, Torii S, Muramatsu T. Expression of midkine in normal and burn sites of rat skin. Burns. (1999) 25:119-24. doi: 10.1016/S0305-4179(98)00120-X

9. Sakakima H, Yoshida Y, Muramatsu T, Yone K, Goto M, Ijiri K, et al. Traumatic injury-induced midkine expression in the adult rat spinal cord during the early stage. J Neurotrauma. (2004) 21:471-7. doi: 10.1089/089771504323004610

10. Krzystek-Korpacka M, Mierzchala M, Neubauer K, Durek G, Gamian A. Midkine, a multifunctional cytokine, in patients with severe sepsis and septic shock: a pilot study. Shock. (2011) 35:471-7. doi: 10.1097/SHK.0b013e3182086001

11. Fischer V, Kalbitz M, Muller-Graf F, Gebhard F, Ignatius A, Liedert $\mathrm{A}$, et al. Influence of menopause on inflammatory cytokines during murine and human bone fracture healing. Int J Mol Sci. (2018) 19:2070. doi: 10.3390/ijms19072070

12. Haffner-Luntzer M, Heilmann A, Rapp AE, Roessler R, Schinke T, Amling M, et al. Antagonizing midkine accelerates fracture healing in mice by enhanced bone formation in the fracture callus. Br J Pharmacol. (2016) 173:2237-49. doi: 10.1111/bph.13503

13. Haffner-Luntzer M, Kemmler J, Heidler V, Prystaz K, Schinke T, Amling M, et al. Inhibition of midkine augments osteoporotic fracture healing. PLoS ONE. (2016) 11:e0159278. doi: 10.1371/journal.pone.0159278

14. Kitahara T, Shishido T, Suzuki S, Katoh S, Sasaki T, Ishino M, et al. Serum midkine as a predictor of cardiac events in patients with chronic heart failure. J Card Fail. (2010) 16:308-13. doi: 10.1016/j.cardfail.2009.12.014

15. Przybylowski P, Malyszko J, Malyszko JS. Serum midkine is related to NYHA class and cystatin C in heart transplant recipients. Transplant Proc. (2010) 42:3704-7. doi: 10.1016/j.transproceed.2010.08.026

16. Reynolds PR, Mucenski ML, Le Cras TD, Nichols WC, Whitsett JA. Midkine is regulated by hypoxia and causes pulmonary vascular remodeling. J Biol Chem. (2004) 279:37124-32. doi: 10.1074/jbc.M405254200

17. Fukui S, Kitagawa-Sakakida S, Kawamata S, Matsumiya G, Kawaguchi $\mathrm{N}$, Matsuura $\mathrm{N}$, et al. Therapeutic effect of midkine on cardiac remodeling in infarcted rat hearts. Ann Thorac Surg. (2008) 85:562-70. doi: 10.1016/j.athoracsur.2007.06.002

18. Netsu S, Shishido T, Kitahara T, Honda Y, Funayama A, Narumi T, et al. Midkine exacerbates pressure overload-induced cardiac remodeling. Biochem Biophys Res Commun. (2014) 443:205-10. doi: 10.1016/j.bbrc.2013.11.083

19. Horiba M, Kadomatsu K, Yasui K, Lee JK, Takenaka H, Sumida A, et al. Midkine plays a protective role against cardiac ischemia/reperfusion injury through a reduction of apoptotic reaction. Circulation. (2006) 114:1713-20. doi: 10.1161/CIRCULATIONAHA.106.632273
20. Sumida A, Horiba M, Ishiguro $\mathrm{H}$, Takenaka $\mathrm{H}$, Ueda $\mathrm{N}$, Ooboshi $\mathrm{H}$, et al. Midkine gene transfer after myocardial infarction in rats prevents remodelling and ameliorates cardiac dysfunction. Cardiovasc Res. (2010) 86:113-21. doi: $10.1093 / \mathrm{cvr} / \mathrm{cvp} 386$

21. Kadomatsu K, Bencsik P, Gorbe A, Csonka C, Sakamoto K, Kishida S, et al. Therapeutic potential of midkine in cardiovascular disease. Br J Pharmacol. (2014) 171:936-44. doi: 10.1111/bph.12537

22. Badila E, Daraban AM, Tintea E, Bartos D, Alexandru N, Georgescu A. Midkine proteins in cardio-vascular disease. Where do we come from and where are we heading to? Eur J Pharmacol. (2015) 762:464-71. doi: 10.1016/j.ejphar.2015.06.040

23. Weckbach LT, Grabmaier U, Uhl A, Gess S, Boehm F, Zehrer A, et al. Midkine drives cardiac inflammation by promoting neutrophil trafficking and NETosis in myocarditis. J Exp Med. (2019) 216:350-68. doi: 10.1084/jem.20181102

24. Abrams ST, Zhang N, Manson J, Liu T, Dart C, Baluwa F, et al. Circulating histones are mediators of trauma-associated lung injury. Am J Respir Crit Care Med. (2013) 187:160-9. doi: 10.1164/rccm.201206-1037OC

25. Kalbitz M, Amann EM, Bosch B, Palmer A, Schultze A, Pressmar J, et al. Experimental blunt chest trauma-induced myocardial inflammation and alteration of gap-junction protein connexin 43. PLOS ONE. (2017) 12:e0187270. doi: 10.1371/journal.pone.0187270

26. Kellum JA, Song M, Venkataraman R. Hemoadsorption removes tumor necrosis factor, interleukin-6, and interleukin-10, reduces nuclear factor- $\kappa B$ DNA binding, and improves short-term survival in lethal endotoxemia. Crit Care Med. (2004) 32:801-5. doi: 10.1097/01.CCM.0000114997.39857.69

27. Born F, Pichmaeier M, Peter S. Systemic inflammatory response syndrome in heart surgery: new possibilities for treatment through the use of a cytokine adsorber during ECC? Kardiotechnik. (2014) 14:1-10.

28. Hetz H, Berger R, Recknagel P, Steltzer H. Septic shock secondary to beta-hemolytic streptococcus-induced necrotizing fasciitis treated with a novel cytokine adsorption therapy. Int J Artif Organs. (2014) 37:422-6. doi: 10.5301/ijao.5000315

29. Hinz B, Jauch O, Noky T, Friesecke S, Abel P, Kaiser R. CytoSorb, a novel therapeutic approach for patients with septic shock: a case report. Int J Artif Organs. (2015) 38:461-4. doi: 10.5301/ijao.5000429

30. Kogelmann K, Drüner M, Jarczak D. Case study of 8 patients with multiple organ failure treated additionally with CytoSorbents haemadsorption as adjunctive therapy in septic shock and severe SIRS in cardiac failure. Germany Infect. (2015) 43:1-73.

31. Gruda MC, Ruggeberg KG, O’Sullivan P, Guliashvili T, Scheirer AR, Golobish TD, et al. Broad adsorption of sepsis-related PAMP and DAMP molecules, mycotoxins, and cytokines from whole blood using CytoSorb(R) sorbent porous polymer beads. PLoS ONE. (2018) 13:e0191676. doi: 10.1371/journal.pone.0191676

32. von Elm E, Altman DG, Egger M, Pocock SJ, Gotzsche PC, Vandenbroucke JP. The Strengthening the Reporting of Observational Studies in Epidemiology (STROBE) statement: guidelines for reporting observational studies. J Clin Epidemiol. (2008) 61:344-9. doi: 10.1016/j.jclinepi.2007.11.008

33. Horst K, Simon TP, Pfeifer R, Teuben M, Almahmoud K, Zhi Q, et al. Characterization of blunt chest trauma in a long-term porcine model of severe multiple trauma. Sci Rep. (2016) 6:39659. doi: 10.1038/srep39659

34. Eschbach D, Steinfeldt T, Hildebrand F, Frink M, Scholler K, Sassen M, et al. A porcine polytrauma model with two different degrees of hemorrhagic shock: outcome related to trauma within the first 48 h. Eur J Med Res. (2015) 20:73. doi: 10.1186/s40001-015-0162-0

35. Horst K, Eschbach D, Pfeifer R, Hubenthal S, Sassen M, Steinfeldt T, et al. Local inflammation in fracture hematoma: results from a combined trauma model in pigs. Mediators Inflamm. (2015) 2015:126060. doi: 10.1155/2015/126060

36. Artimovich E, Jackson RK, Kilander MBC, Lin YC, Nestor MW. PeakCaller: an automated graphical interface for the quantification of intracellular calcium obtained by high-content screening. BMC Neurosci. (2017) 18:72. doi: 10.1186/s12868-017-0391-y

37. Ballard-Croft C, Carlson D, Maass DL, Horton JW. Burn trauma alters calcium transporter protein expression in the heart. J Appl Physiol. (2004) 97:1470-6. doi: 10.1152/japplphysiol.01149.2003

38. Tanaka T, Kanda T, Takahashi T, Saegusa S, Moriya J, Kurabayashi M. Interleukin-6-induced reciprocal expression of SERCA and natriuretic 
peptides mRNA in cultured rat ventricular myocytes. J Int Med Res. (2004) 32:57-61. doi: 10.1177/147323000403200109

39. Duncan DJ, Yang Z, Hopkins PM, Steele DS, Harrison SM. TNF- $\alpha$ and IL$1 \beta$ increase $\mathrm{Ca}^{2+}$ leak from the sarcoplasmic reticulum and susceptibility to arrhythmia in rat ventricular myocytes. Cell Calcium. (2010) 47:378-86. doi: 10.1016/j.ceca.2010.02.002

40. Zhang C, Mo M, Ding W, Liu W, Yan D, Deng J, et al. High-mobility group box 1 (HMGB1) impaired cardiac excitation-contraction coupling by enhancing the sarcoplasmic reticulum (SR) $\mathrm{Ca}(2+)$ leak through TLR4ROS signaling in cardiomyocytes. J Mol Cell Cardiol. (2014) 74:260-73. doi: 10.1016/j.yjmcc.2014.06.003

41. Kalbitz M, Schwarz S, Weber B, Bosch B, Pressmar J, Hoenes FM, et al. Cardiac depression in pigs after multiple trauma - characterization of posttraumatic structural and functional alterations. Sci Rep. (2017) 7:17861. doi: 10.1038/s41598-017-18088-1

42. Fattahi F, Frydrych LM, Bian G, Kalbitz M, Herron TJ, Malan EA, et al. Role of complement C5a and histones in septic cardiomyopathy. Mol Immunol. (2018) 102:32-41. doi: 10.1016/j.molimm.2018.06.006

43. He H, Giordano FJ, Hilal-Dandan R, Choi DJ, Rockman HA, McDonough $\mathrm{PM}$, et al. Overexpression of the rat sarcoplasmic reticulum $\mathrm{Ca}^{2+}$ ATPase gene in the heart of transgenic mice accelerates calcium transients and cardiac relaxation. J Clin Invest. (1997) 100:380-9. doi: 10.1172/JCI1 19544

44. Vetter R, Rehfeld U, Reissfelder C, Weiss W, Wagner KD, Gunther J, et al. Transgenic overexpression of the sarcoplasmic reticulum $\mathrm{Ca}^{2+}$ ATPase improves reticular $\mathrm{Ca}^{2+}$ handling in normal and diabetic rat hearts. FASEB J. (2002) 16:1657-9. doi: 10.1096/fj.01-1019fje

45. Tatsumi T, Matoba S, Kawahara A, Keira N, Shiraishi J, Akashi K, et al. Cytokine-induced nitric oxide production inhibits mitochondrial energy production and impairs contractile function in rat cardiac myocytes. J Am Coll Cardiol. (2000) 35:1338-46. doi: 10.1016/S0735-1097(00) 00526-X

46. Shen YL, Shi YZ, Chen GG, Wang LL, Zheng MZ, Jin HF, et al. TNF- $\alpha$ induces Drp1-mediated mitochondrial fragmentation during inflammatory cardiomyocyte injury. Int J Mol Med. (2018) 41:2317-27. doi: 10.3892/ijmm.2018.3385

47. Boyd JH, Mathur S, Wang Y, Bateman RM, Walley KR. Toll-like receptor stimulation in cardiomyoctes decreases contractility and initiates an NFКB dependent inflammatory response. Cardiovasc Res. (2006) 72:384-93. doi: 10.1016/j.cardiores.2006.09.011

48. Bruns B, Maass D, Barber R, Horton J, Carlson D. Alterations in the cardiac inflammatory response to burn trauma in micelacking a functional Toll-like receptor 4 gene. Shock. (2008) 30:740-6. doi: 10.1097/SHK.0b013e3181 $73 \mathrm{f} 329$

49. Avlas O, Fallach R, Shainberg A, Porat E, Hochhauser E. Toll-like receptor 4 stimulation initiates an inflammatory response that decreases cardiomyocyte contractility. Antioxid Redox Signal. (2011) 15:1895-909. doi: 10.1089 /ars.2010.3728

50. Darrabie MD, Cheeseman J, Limkakeng AT, Borawski J, Sullenger BA, Elster EA, et al. Toll-like receptor activation as a biomarker in traumatically injured patients. J Surg Res. (2018) 231:270-7. doi: 10.1016/j.jss.2018.05.059

51. Gao H, Yin J, Shi Y, Hu H, Li X, Xue M, et al. Targeted P2X7 R shRNA delivery attenuates sympathetic nerve sprouting and ameliorates cardiac dysfunction in rats with myocardial infarction. Cardiovasc Ther. (2017) 35. doi: 10.1111/1755-5922.12245

52. Owada K, Sanjo N, Kobayashi T, Mizusawa H, Muramatsu H, Muramatsu T, et al. Midkine inhibits caspase-dependent apoptosis via the activation of mitogen-activated protein kinase and phosphatidylinositol 3-kinase in cultured neurons. J Neurochem. (1999) 73:2084-92. doi: 10.1046/j.1471-4159.1999.02084.x

53. Ohuchida T, Okamoto K, Akahane K, Higure A, Todoroki H, Abe Y, et al. Midkine protects hepatocellular carcinoma cells against TRAIL-mediated apoptosis through down-regulation of caspase-3 activity. Cancer. (2004) 100:2430-6. doi: 10.1002/cncr.20266

54. Houschyar KS, Pyles MN, Rein S, Nietzschmann I, Duscher D, Maan $\mathrm{ZN}$, et al. Continuous hemoadsorption with a cytokine adsorber during sepsis - a review of the literature. Int J Artif Organs. (2017) 40:205-11. doi: 10.5301/ijao.5000591

55. Haffner-Luntzer M, Fischer V, Prystaz K, Liedert A, Ignatius A. The inflammatory phase of fracture healing is influenced by oestrogen status in mice. Eur J Med Res. (2017) 22:23. doi: 10.1186/s40001-017-0264-y

Conflict of Interest Statement: The authors declare that the research was conducted in the absence of any commercial or financial relationships that could be construed as a potential conflict of interest.

Copyright (C) 2019 Lackner, Weber, Baur, Haffner-Luntzer, Eiseler, Fois, Gebhard, Relja, Marzi, Pfeifer, Halvachizadeh, Lipiski, Cesarovic, Pape, Kalbitz and TREAT Research Group. This is an open-access article distributed under the terms of the Creative Commons Attribution License (CC BY). The use, distribution or reproduction in other forums is permitted, provided the original author(s) and the copyright owner(s) are credited and that the original publication in this journal is cited, in accordance with accepted academic practice. No use, distribution or reproduction is permitted which does not comply with these terms. 